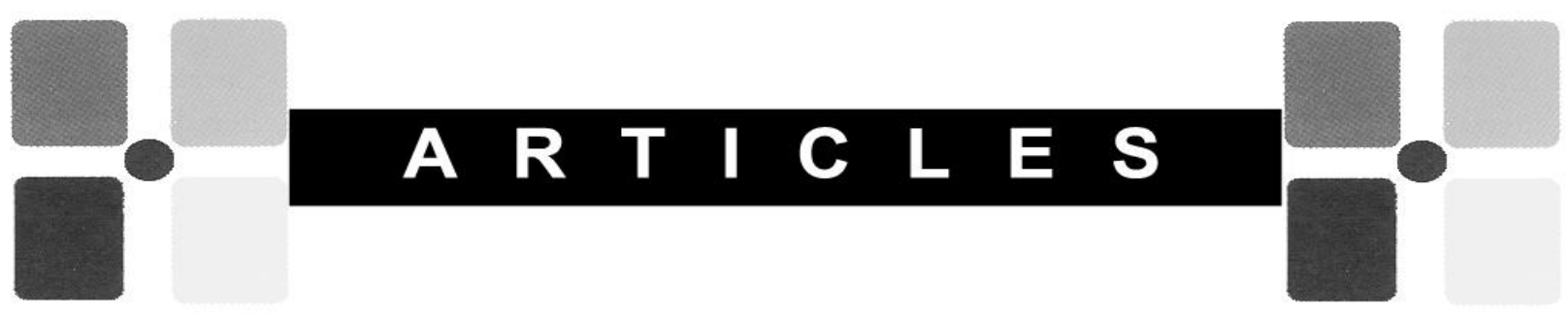

\title{
Credit Where Credit is Due: Considering Ethics, Ethos, and Process in Library Instruction on Attribution
}

\author{
By Benjamin R. Harris, Trinity University
}

\begin{abstract}
Numerous reasons have been offered for the increase in plagiarism in the academy over the last decade, and most of the research has assigned primary blame to the influence of the Internet. Few writers have considered how changes in the location of research and citation instruction have had an impact on these statistics. The lack of such instruction in first-year writing courses, spurred by changes in pedagogical theory on the teaching of composition, has been a powerful but subtle influence on how (or even if) research process is truly taught to undergraduates. Further, as librarians have adopted and deployed information literacy initiatives in their institutions, their responsibilities related to the ethical and effective use of sources have grown. Considering options for instructing students "how" and "why" they will want to use sources will help teaching librarians achieve their information literacy initiatives and prepare for the new and changing roles they will accept in their institution's educational mission.
\end{abstract}

\section{Introduction}

Many library professionals educated pre-Web would agree that there was a time when plagiarism seemed uncommon. One remembers the unsophisticated efforts of a random student copying from an encyclopedia entry, or "borrowing" the paper of another writer and claiming it as his or her own. The rules and definitions for cheating were cut and dried, and the reasoning behind the activity seemed plain: the student couldn't or wouldn't do the work.

As librarians, teaching faculty, and administrators are well aware, the ways and means that characterize plagiaristic action have become far more complex. Statistics consistently show that cases of reported plagiarism have increased over the last 10 years, and research conducted by the Center for Academic Integrity (2003) concluded that "while $10 \%$ of students admitted to engaging in such behavior in 1999, this rose to $41 \%$ in a 2001 survey with the majority of students (68\%) suggesting this was not a serious issue." Many educators make the connection between the rise in plagiarism and the influence of the web, and this is a reasonable causal link. Paper mills and websites presenting student work that might never have been seen beyond the eyes of one student and one instructor contribute to the problem. The transient and unregulated character of online publications and the vast electronic spaces where texts become lost or difficult to retrace are other factors. In the end, one may surmise that while students can do the work, the lure of an easy way out or through an assignment is inordinately tempting.

\section{Other Factors}

Clearly, the Internet has had an influence on the ease of cheating. Greater connectivity leads to greater opportunity and requires a greater sense of responsibility. This is true for all Internet users. Anyone surfing the Net has the potential to use or misuse and abuse the intellectual and copyrighted property of others, and students are no exception. Lax attitudes related to copyright and intellectual property may contribute to greater numbers of reported incidents of plagiarism. ${ }^{2}$ However, among college and university students there are other reasons for a rise in these statistics. Rarely considered are the changes in the 
traditional locations for the teaching of research methods and citation, and the substantive revisions and reevaluations of the theory and practice taking place in these academic disciplines. In particular, shifts in the teaching of composition should be considered, since at one time this was the primary location for first or second year instruction in research methods, citation, and ethics.

While the immediate connection may not be obvious, a shift away from instruction that focused on mechanical or skill-based tasks such as grammar instruction and the teaching of citation method resulted in less rigorous attention to the development of these abilities. Textbooks and writing handbooks were given (sole) authority to guide students through these tasks, even though the pedagogical value of these texts was questionable.

With the fall of the current-traditional paradigm for the teaching of writing, mechanics-focused instruction fell out of favor. As THE mode for writing instruction before the 1960s, the current-traditional paradigm was characterized by its devotion to the prescriptive 5-paragraph theme (which still exists in some quarters regardless of the fact that it is ill-suited to critical, independent, thoughtful writing). ${ }^{3}$ Cookie-cutter outlining, a lack of invention strategies, and a dependence on the innate (and unexplainable and unteachable) "reason" of the writer without allowing for a drafting process as a means of completing writing assignments are just a few characteristics of this wizened form of instruction. ${ }^{4}$

The process writing movement would follow in the 1960s and 1970s. The process movement didn't actually replace the current-tradition, but it did respond to its influence. Teachers of process focused more on the invention and revision methods of writers and the creative moves made during the writing of multiple drafts, while deemphasizing the importance of the polished final product. Prescriptive, skills-based philosophies were as absent during the process movement as they were characteristic of older philosophies. But by the late 1980s, the "drafting is good for you" school of instruction began to look more like kin than corrective to the current-tradition.

As technology has become an intrinsic component in most writers' practices and as it has had a profound influence on the teaching of writing, composition pedagogy is embracing the "post-process" movement. In post-process pedagogy, the best practices of the current-tradition (focus on product) and the process movement (focus on process) are being combined and reformulated as the influence of machines change the way writer's compose. With the contemporary popularity of this hybrid pedagogy, some skill-based activities have been invited to return to the writing classroom.

In "Welcoming Grammar Back into the Writing Classroom," Bonnie Devet (2002) offers an abbreviated account for how grammar instruction in particular was erased, or at the very least, frowned upon by teachers of composition during the process movement. Devet claims that the skills-and-drills quality of the instruction and the grading of work based on "correctness" as opposed to critical thinking and writing were primary factors in the devaluation of these topics (9). In today's post-process climate, including skillsbased instruction in the writing classroom is not only more acceptable, but is viewed as necessary topics of instruction for the contemporary student writer.

And yet, while Devet may be welcoming grammar back into the classroom in ways that steer clear of skills-and-drills instruction, similar instruction on the use and citation of sources has yet to be welcomed. Further, other courses of study traditionally offered to first and second-year students are not eager to assume the responsibility. By all appearances, the responsibility has been assigned to and accepted by the library.

\section{But Why Not Teaching Faculty?}

Claims that instruction in avoiding plagiarism and correct attribution of source materials have become the domain of libraries begs the question - why librarians as opposed to teaching faculty? Why is there not a "citing across the curriculum" movement sweeping college campuses? An initial reason is that teaching faculty across disciplines are unaccustomed to offering extended instruction related to the use of research sources. Scholars in most disciplines have only included comments in the margins of graded papers, or mentioned the peculiarities of using and citing sources within particular areas of study. But beyond a lack of experience or interest in spending class time and preparation on this topic, there are also pedagogical reasons that would discourage this instruction across disciplines. 
First, citation instruction will be linked to the topic of plagiarism, and likewise, to processes involved in catching cheaters. At times and in some situations or institutions, this encourages a "seek and destroy" mentality that insinuates itself into the student-teacher relationship. As Stuart Selber (2004: 110) contends, "the software environments involved in plagiarism cases can also encourage pedagogical styles based on control and fear." A culture of surveillance is associated with the work of fingering and tracking writers who plagiarize, a situation in which "surveillance often substitutes for compassion, content knowledge, and engagement" (2004: 110). Instead of teaching and mentoring students, faculty may shift into these "corrections officer" positions.

Another concern for faculty may be the impact of focusing on attribution when students need as much or more attention given to the presentation of ideas and the construction of cogent arguments in their written work. Teachers' comments, in class and on paper, are an influential component in students' drafting and learning processes. 'Teachers' comments can take students' attention away from their purposes in writing a particular text and focus that attention on the teachers' purpose in commenting" (Sommers, 1982: 12). Therefore, a focus on citation may suggest to students that the periods and commas in a bibliographic entry are as valuable as the ideas or arguments presented in their essays. And while one would not want to create a hierarchical structure of value based on what is more or less important in students' writing and research, teaching faculty would not want to lose an instructional avenue or teaching opportunity in these symbiotic processes of writing, researching, reading, and responding.

With its absence from the curricula of many writing classes, and with growing concerns related to plagiarism and the ability of students to use research in an ethical manner, the work of involving students in experiences that develop their abilities as ethical users of information must being reassigned. The library setting is a comfortable academic location for this reassignment. Not only is it a more comfortable location for teaching faculty, but librarians and information professionals are already offering training related to these topics as they include information literacy instruction in their libraries and across campuses. For institutions and librarians accepting the opportunities of new topics and methods in instruction related to information literacy, resisting the role of bibliographic corrections officers becomes a concern.

\section{Librarians Teaching Citation}

Most would agree that the traditional library has not ignored the need for tools and instruction related to citation method. When bibliographic instruction was $\mathrm{BI}$ and online resources for citing sources were just a dream, the library often functioned as the storehouse for print guidelines on citation style (those published and those created on-site as pathfinders for individual academic communities). In addition, certain amounts of instruction and reminders regarding citation methods were a standard inclusion in the BI lecture, and the reference desk has been a stalwart champion of correct citation mechanics.

More recently, software and web-based systems of assisting with the work of citation have been developed and embraced. These resources are indeed valuable. They save time and reduce errors in citation format. However, any philosophy behind giving attribution is completely lost with the deployment of these tools. In their efforts to make citations tasks more efficient and error-free, programs such as InCite and RefWorks remove some of the intellectual work of including sources in student writing.

Beyond the fact that considering citation in relation to the research process has always existed in the domain of libraries in some fashion, library educators and professionals have asked for greater responsibility in relation to the ethical use of sources. One component of the guidelines for the information literate individual is consideration for how information is "used," and "using" a source in a project or paper will clearly require citation. As a component of information literacy instruction on the use of sources, instruction as well as appropriate learning objects is necessary to assist students as they use information.

However, as many library professionals already dealing with the topic have found, answers for how "best" to teach citation method often become enterprises in trial and error. Skills and drills tasks that ask students to complete handouts and compare this citation to that are only so engaging, and only somewhat purposeful in an instructional setting. Now more than ever, it is vital for students to comprehend both the "how" and the "why" behind the attribution of sources. 


\section{Teaching "How"}

The "how" of attribution has been taught for decades in one location or another, and while this amounts to teaching researchers how to "fill in the blanks" of citation guidelines, the value of "how" instruction should not be completely disregarded. Difficulties in learning and completing correct citation method tend to occur during the process of three citation process tasks. Learners make errors when: (1) they are unable to determine and use the correct citation based on the format of the text they wish to cite $^{5} ;(2)$ they are unable to find the information to include in a citation ${ }^{6}$; and (3) they lose the connection between the information they use in their project or paper and the citation they include in their bibliography. Considering these common stumbling blocks, comprehending the "how" of citation instruction requires integrated, taskbased instruction. The learning styles of most students will require that for these tasks to appear valuable, they must be directly related to the project for which they will receive a score.

In teaching the "how," one must also consider the very existence of different citation styles. Different citation styles are in place because they fulfill the needs of certain academic disciplines and topics in the academy. This very basic understanding of why there is more than one style and why these styles differ will escape most writers. The minutiae related to differing formats for citation relate directly to the purposes of the community involved in creating the style. For example, the style guide for the Modern Languages Association (MLA) - a style developed by teachers and professionals in the humanities - offers the full name of the author as its first component in almost any Works Cited entry. The full title of the work in its published form is included after the author's name.

Likewise, the style of the American Psychological Association (APA), a group of researchers in the Social Sciences often involved in quantitative research, abbreviates the author's first name and follows with the date of publication. For this group of researchers, the name is reduced in importance; the date of publication is clearly of greater value to members of this community as it shows the timeliness of the material in relation to the topic. For researchers in the MLA, the date is valuable but not as valuable as other information included in the citation. A source that is 300 years old in a paper on Chaucer's Canterbury Tales may be just as useful as a recent scholarly article on the topic. Helping researching writers understand that these stipulative rules for citation are directly related to the goals and needs for the communities that create the citation style can help them understanding that the "how" of citation is not a creative endeavor.

\section{Answering the "Why"}

Underlying the rules and protocols guiding the mechanics of citation styles are the more subtle (and often invisible) philosophies for "why" we offer attribution to our sources. If asked to consider this question, students will often generate a number of reasons for why they cite:

- to avoid plagiarism

- to follow the directions and guidelines given by an instructor, in a class, or in a specific academic community.

Instructors might encourage students to think about other components of attribution philosophy that may be less apparent. These considerations might include:

- allowing the reader an opportunity to see related sources that would allow the reader to continue their learning on the topic

- allowing the reader an opportunity to see related sources so that they may review the current discussion and consider how the conversation may continue

- allowing the reader to see a writer's authority on a topic by offering the resources referenced during the writer's line of inquiry

- giving credit to the authors whose intellectual property have been valuable in the construction of new texts

- participating in the traditions of the academy and of scholars who, like students today, gave credit to their resources

- $\quad$ situating the writer's work within the other voices and discussions on the topic

- encouraging readers to participate in the discussion by writing their own essay or response.

Other considerations are also possible, and instructors may be surprised when students hit upon inventive lines of reasoning for using and giving attribution to their sources. And still, these different reasons for 
offering attribution seem to follow certain ways of thinking about writing and research. By looking at consistencies across the lines of reasoning listed above, two specific topics of concern for writers are being addressed: the ethics of using sources, and the construction of the writer's ethos through the use of sources.

\section{Ethics and Ethos}

The ethical imperative for diligent, correct attribution of sources is well documented ${ }^{7}$ and the tasks of (1) avoiding plagiarism and (2) following directions relate to the goal of using sources in an ethical manner. Further, topics related to avoiding plagiarism and academic integrity have become common concerns for librarians, teaching faculty, and administrators, et al. In the end, the challenge behind instruction related to avoiding plagiarism is simple: students know it is wrong to steal and it is wrong to cheat. Writers know this before they ever enter the classroom. Rarely will students have no concept that these activities act against their own interest and the interests of educators. A focus on this line of instruction is then moot.

At a time when writers have greater opportunity to steal, they require more reasons to refrain from stealing. ${ }^{8}$ This is not to suggest that instruction related to the ethics of using sources lacks value. Instead, it may be that alternative instruction topics should be considered that focus on how the ethical use of sources benefits students. One option suggested in the list above focuses on the character and identity of the writer as it is presented in his or her work and how the use of sources is related to this presentation of character and identity.

The concept of ethos, or the appeal to the reader's sense of the writer's character, is one of the persuasive strategies described by Aristotle (1991) some 2500 years ago, and it continues to be of great use for contemporary writers and rhetors. ${ }^{9}$ While the writer's ethos may be constructed entirely by his or her words and ideas, the other voices they include in their work and with which they converse will have a direct correlation with the reader's sense of the writer's character. A writer whose bibliography includes well respected authorities on a topic may appear to have covered their research "bases." A writer whose research sources show a clear lack of concern for the research and attribution process, and in turn, for the quality of their work, is another kind of ethos.

It is true that the reader's sense of the writer's character can be misleading. One can find authoritative sources and have nothing to say that is new or independent of those other voices. In addition, a student may have brilliant ideas but may not have a clear concept for how to find the best sources on a particular topic or in a specific field of study. Both of these situations offer opportunities for further instruction.

Ultimately, instruction and discussion related to how the correct use of sources speaks about the writer's character "sells" with students. It speaks to their immediate goals for taking a course or pursuing a line of study, and ultimately these goals involve improving their writing and research capabilities in order to receive a satisfying grade, fulfill a component of their degree plan, and graduate into other courses. As students move forward, and especially for those pursuing post baccalaureate degrees, they will reconsider the reasons behind why they write and how this relates to the use and citation of sources. As student writers endeavor deeper into the creative and critical methods required of scholarly writing, the purpose behind writing and research become more complex.

\section{Writing, Citing and Creative-Critical Process}

At first year and other undergraduate levels, the philosophy behind citation does not always include how research and attribution are involved in research and writing as scholarly activities. Attribution of sources and sometimes even the use of sources are activities completed after the essay has been written. As feared by process and even post-process teachers of composition, the work of attribution then becomes an exercise in skills and drills, an experiment in cutting and pasting.

Student writers must understand that the use of sources that speak for or against the his or her ideas adds value to academic writing. This is clearly more than a "skills and drills" process, and the work of attribution is tied to this value; it cannot be separated. Just as a brilliant paper lacking attention to grammatical correctness loses its functionality, its power, and its persuasive appeal, a paper that uses sources improperly suffers the same loss. Attribution is directly tied to the writing process, a process that requires 
creative impulse and critical thinking. With this in mind, it is helpful to consider how sources are often used in scholarly writing.

- A source is used to confirm a claim made by the author.

- A source is used as counterpoint and might be utilized in building an author's refutation of another belief (one commonly held or one that is singular to a specific text).

- A source is used in relation with the writer's ideas to develop a conversation or engage in discussion with the source about a particular topic.

The first two examples of the use of sources exhibit traditional, hierarchical philosophies of the use of sources. They are characterized by a mechanistic, "fill in the blank" way of thinking, not about the mechanics of citation but about how the information is used in a writer's work. This way of thinking is reductive in light of the discursive activities that characterize the processes of many successful writers. Further, it fails to recognize how student writing has the potential to participate in scholarly communications. Focusing on the conversation enacted by researching writers engaged with their sources suggests an avenue to rethink the mechanistic character of citation.

The third manner of thinking about citation in the previous list speaks to such a focus. Bruce $P$. Ballenger (1999: 127) explores this perspective in Beyond Notecards: Rethinking the Freshman Research Paper.

Students who are used to writing research papers that are argumentative or based on the thesis-example model may see only two moves they might make following a quoted source: signal agreement or disagreement, or offering up the quote as a supporting example. But there are other possibilities, especially for the essay writer. She might circle back to restatein her own words - the idea that is most important to her, or apply that idea to a fresh context [...]. She might pose a question that complicates the author's claims rather than simply register agreement or disagreement. She might simply wonder (in writing) about the possible significance of the idea or the information-how does it change the story she is telling about her topic or the story of her thinking about that topic.

David Franke (1995: 376) uses the term "lateral citation" to describe this style, and defines this form of use and attribution as "one that emphasizes collaboration and connection over argument and defense; that is, an author's identity is often established by connection with others rather than argument against them." Emphasizing research sources as other voices in a conversation also emphasizes the students' addition to the conversation and the agency of their voice. By thinking differently about the sources they use in relation to their ideas and their writing, students will become more diligent in their attribution methods and citation skills.

\section{Toward Solutions}

Discussions that offer solutions to challenges faced by researching writers as well as library and information professionals in relation to attribution methods can and will take place. Institution-specific solutions never work for everyone, everywhere; continued interrogation will allow instructional options that built upon and expand this topic. The following suggestions are not solutions, but rather avenues for thinking about these instructional opportunities.

- Offer instruction that builds on the concept of ethical activities for writers without focusing entirely on avoiding plagiarism. Students are prepared for this topic, they are becoming immune to it, and they require enlightenment. Instruction should expand the topic of plagiarism to include new or unfamiliar reasons behind using and giving attribution to their sources in a conscious and diligent manner.

- Devise instructional opportunities and learning objects that are active, and if possible, directly related to the topics and texts of the course.

- Develop collaborative situations with faculty that reinforce discussions on the use of sources. This may require multiple interactions with classes, or may involve assessing instruction by viewing student work related to the use of sources. The integration of this kind of instruction with the actual work of students is vital to sustain student interest.

- Integrate topics related to attribution and the use of sources with the information literacy missions of libraries and their universities. 
- Reconsider the way conversations related to the use of sources are named. Instruction on the "attribution of sources" or the "integration of research" makes a connection with the desired activity as opposed to an immediate focus on negative or undesirable conduct.

- Reconsider the way conversations related to attribution are sequenced. Timing is imperative, and beginning anything with a discussion of plagiarism suggests immediate suspicion. Responding to Rebecca More Howard's (2002: 46) call that we not "police plagiarism" or buy into the "gotchya industry," directions that distract from the teaching and learning process, librarians and other faculty will want to consider these guidelines as they sequence their instruction.

- Strive to make and present connections between the processes of research, writing, and attribution. Integration of these discursive, recursive situations will help to include the use and citation of sources within a writer's work, and refrain from cut-and-paste, "skills and drills," and "first draft as final draft" mentalities.

The greatest challenge ahead for teaching librarians may be our own re-education on why we write and how we value the use and attribution of sources in relation to our own research. Many of us may find it necessary to reconsider our own methods and attitudes about the use of sources in our writing and related projects. It may be necessary that we become much more proficient in both the "how" and "why" of source attribution. These topics and surrounding discussions will force us to consider how our traditional roles as locators of and directors to information have changed, and may offer insight into the changes that lie ahead.

\section{Notes}

1. See Ercegovac and Richardson's (2004) literature review for statistics related to prevalence of plagiarism as well as student and faculty attitudes related to academic dishonesty.

2. See Auer and Krupar (2001) for a review of contributing factors. Published in 2001, the factors have remain relevant.

3. See Crowley (1990) for extended discussion and critique of the current-traditional paradigm for the teaching of composition.

4. See Welch (1999, chap. 5) for a comparison of the current-tradition as a wizened form of writing instruction when compared to classical techniques that have lasted for millennia.

5. For example, a student citing a PBS documentary on videotape may use the citation for a television program as opposed to the citation method for videotaped materials. There is still a desire to use the citation method for print journal articles when the article was accessed through a subscription database. The issue of format is complicated for anyone using a citation style and will only become more complex as more and more types of materials are offered in a multiplicity of formats.

6. Many will have had the experience of attempting to find the author of a web site or a date on an electronic document with the full belief that the information is presented...somewhere. After print, when the conventions of printed texts allowed writers and citers to quickly and efficiently find the information they needed for citations, locating information for citations of Internet resources can become something akin to an obstacle course.

7. Auer and Krupar, as well as Ercegovac and Richardson, offer valuable literature reviews on this documentation.

8. Aside from the ethical use of the intellectual property of others in academic contexts, comprehension of the "bigger picture" results of the theft of intellectual property has been slow in coming, but continues. Situating the impact of the theft of intellectual property in academic settings with the theft of other kinds of texts (such as music, film, etc.) might be helpful in understanding how theft of any form of intellectual property is damaging, not only to the thief, but to the owner of the property and the community and purpose for which that property has been published.

9. Aristotle (1991) writes of ethos in two ways: the character of the speaker as reasoned by the audience (37-38) and the character of the speaker created or desired by the character (chap. 12-17). The second dynamic is sometimes called "rhetorical ethos." The definition presented in this text, "the reader's sense of the writer's character" recognizes both of these constructions of ethos. 


\title{
References
}

Aristotle. (1991). On rhetoric: A theory of civic discourse (G.A. Kennedy, Trans.). New York: Oxford University Press.

Auer, N.J., \& Krupar, E.M. (2001). Mouse Click Plagiarism: The Role of Technology in Plagiarism And The Librarian's Role In Combating It. Library Trends, 40(3), 415-432.

Ballenger, B.P. (1999). Beyond Note Cards: Rethinking the Freshman Research Paper. Portsmouth: Boynton/Cook.

Center for Academic Integrity. (2003). CAI Research. Retrieved January 17, 2005, from http://www.academicintegrity.org

Crowley, S. (1990). The Methodical Memory: Invention in Current-Traditional Rhetoric. Carbondale: Southern Illinois University Press.

Devet, B. (2002). Welcoming Grammar Back into the Classroom. Teaching English in the Two-Year College (TETYC), 30(1), 8-17.

Ercegovac, Z., \& Richardson, J.V. (2004). Academic Dishonesty, Plagiarism Included, in the Digital Age: A Literature Review. College \& Research Libraries, 65(4), 301-318.

Franke, D. (1995). Writing into Unmapped Territory: The Practice of Lateral Citation. In L.W. Phelps \& J.A. Emig (Eds.), Feminine and Women's Experience in American Composition and Rhetoric. Pittsburgh: University of Pittsburgh Press.

Howard, R.M. (2002). Don't Police Plagiarism: Just TEACH! Education Digest, 67(5), 46-49.

Selber, S. (2004). Multiliteracies for a Digital Age. Carbondale: Southern Illinois University Press.

Sommers, Nancy. (1982). Responding to Student Writing. College Composition and Communication (CCC), 33(2), 12-16.

Welch, K.E. (1999). Electric Rhetoric: Classical Rhetoric, Oralism, and a New Literacy. Cambridge, MA: MIT Press.

Assistant Professor Benjamin Harris is Reference/Instruction Librarian for the Elizabeth Huth Coates Library at Trinity University in San Antonio. His email address is Benjamin.Harris@Trinity.edu

\section{Academic Librarians and Student Affairs Professionals: An Ethical Collaboration for Higher Education}

\author{
By Laura Urbanski Forrest, California State University Long Beach
}

\begin{abstract}
Librarians' ethical directives point toward a collaborative effort in providing support for students outside the classroom. Academic librarians often focus on collaborative relationships with teaching faculty at institutions of higher education, but they should also form partnerships with other higher education professionals. Currently, few such partnerships have been reported in the literature. Staff who work in student affairs, including academic advising, career counseling, and other academic support offices would benefit greatly from librarians' expertise. Specific suggestions for building such collaborations are given, and proposals about future research and possible collaborations are offered.
\end{abstract}

\section{Introduction}

Librarians' ethical directives and standards point toward a collaborative effort with teaching faculty in providing support for students (American Library Association., 1995; American Library Association., 2005) as do the professional standards of student affairs professionals (American College Personnel Association, 